\title{
Comparison of Different Catalysts for Fermentative Hydrogen Production
}

\author{
Pornthip Wimonsong and Rachnarin Nitisoravut
}

\begin{abstract}
The activity of different catalysts namely, Mg-Al hydrotalcite (HT), Au/Zn-Mg-Al HT and nanoporous activated carbon (NAC) were tested in batch fermentative production of hydrogen using sucrose-fed anaerobic mixed culture at $37^{\circ} \mathrm{C}$. The catalysts activity for fermentative hydrogen production is in order of Au/Zn-Mg-Al HT > NAC > Mg-Al HT. It has been found that the modified HT with Zn supported Au catalyst improved the bioactivity of hydrogen producing bacteria as compared to unmodified HT. This behavior probably is related to the combination effects of the metallic dispersion of Au on the support surface containing $\mathrm{Zn}$, which can act as the active site of several enzymes, including hydrogenase. The Au/Zn-Mg-Al HT exhibited the maximum hydrogen yield of $2.74 \pm 0.14 \mathrm{~mol}$ $\mathrm{H}_{2} / \mathrm{mol}$ sucrose at applied catalyst dosage of $167 \mathrm{mg} / \mathrm{L}$. The difference in properties of catalysts was speculated to be the cause of variation of soluble metabolites. High initial activity of NAC for hydrogen production accompanied with a high concentration of acetic acid. In the case of metal catalysts, a mixture of acetic acid and butyric acid were detected. In contrast, a lower concentration of butyric acids was observed in NAC test. The result suggested that the presence of NAC could minimize the concentration of butyric acid in fermentation broth with high capacity of absorption up to $77 \%$.
\end{abstract}

Index Terms-Hydrotalcites, gold, activated carbon, biohydrogen production.

\section{INTRODUCTION}

Biological processes served as alternative routes for hydrogen production due to its environmental benefits. Biohydrogen can produce through dark fermentation with various types of wastes such as food waste [1], industrial waste [2], and wastewater [3]. Moreover, it is relatively simple with a lower operating cost than photo fermentation. However, hydrogen yields reported in the literatures was lower than theoretical yields [4], [5]. The highest theoretical yield of hydrogen is $4 \mathrm{~mol} \mathrm{H}_{2} / \mathrm{mol}$ glucose, when acetic acid is the end-product. In practice, the yields are low since the end products contain both acetic acid and butyric acid. Besides organic acids, reduced end-products such as lactic acid are also produced that cause low hydrogen yields. In addition, the accumulation of soluble acid metabolites in fermentation broth inhibits the process of hydrogen production with a sharp drop in the system $\mathrm{pH}$. Improvements of the bioactivity of hydrogen producing bacteria as well as the avoidance of end-product inhibition are needed to achieve a high yield of hydrogen production. The role of nanotechnology is receiving more attention in enhancing the process efficiency in fermentative hydrogen

Manuscript received November 25, 2013; revised March 9, 2014.

Rachnarin Nitisoravut is with School of Bio-Chemical Engineering and Technology, Sirindhorn International Institute of Technology, Thammasat University, Pathum Thani 12121, Thailand (e-mail: snitisor@ siit.tu.ac.th). production such as electron transfer using 5-nm-gold particles [6], an activator to recover the bioactivity from mesoporous $\mathrm{Fe}_{3} \mathrm{O}_{4}$ [7], cell immobilization on $\mathrm{FeCO}_{3}$ [8], and $\mathrm{Mg}^{2+}$ to facilitate the electron transfer process of $\mathrm{Mg}-\mathrm{Al}$ hydrotalcite (HT) [9]. Among nanomaterials used in the literatures, gold catalyst shows the highest hydrogen yield of $4.48 \mathrm{~mol} \mathrm{H}_{2} / \mathrm{mol}$ sucrose. In this study the catalysts namely, Mg-Al HT, Au/Zn-Mg-Al HT and nanoporous activated carbon (NAC) were investigated for affecting on the biohydrogen production and the distribution of metabolites in fermentative process. The catalysts were compared based on their enhancement in biohydrogen production.

\section{MAterials AND Methods}

\section{A. Catalyst Preparation}

The unmodified Mg-Al HT was prepared as described in our previous study [9]. Au catalysts were prepared by the incipient impregnation method over modified Mg-Al HT with $\mathrm{Zn}$ as support. An aqueous solution of $0.1 \mathrm{~g} \mathrm{HAuCl}_{4}$ in $10 \mathrm{~mL}$ of ethanol was added dropwise to $12 \mathrm{~g}$ of the HT support under continuous mixing. The support was dried for $24 \mathrm{~h}$ at $50^{\circ} \mathrm{C}$ and then subsequently heated at $100^{\circ} \mathrm{C}$ for $4 \mathrm{~h}$. After that HT supported gold was calcined at $350^{\circ} \mathrm{C}$ for $4 \mathrm{~h}$. In case of the carbon catalyst, NAC was obtained from National Nanotechnology Center, Thailand. It was granular shape with a pore diameter of $0.69 \mathrm{~nm}$.

\section{B. Inoculum and Medium}

Mixed culture anaerobic sludge was obtained from brewery wastewater treatment plant. The $\mathrm{pH}$, volatile suspended solids (VSS), and total suspended solids (TSS) concentrations of the anaerobic sludge were 7.16, $11.5 \mathrm{~g} / \mathrm{L}$, and $16.3 \mathrm{~g} / \mathrm{L}$, respectively. The chemical oxygen demand (COD) concentration of anaerobic sludge was $13.2 \mathrm{~g} \mathrm{COD} / \mathrm{L}$. The sludge was heated at $105^{\circ} \mathrm{C}$ for $30 \mathrm{~min}$ in order to remove methanogenic bioactivity. A synthetic wastewater consisting of sucrose solution at a concentration of $24.3 \mathrm{~g}$ $\mathrm{COD} / \mathrm{L}$ and nutrient solution as described in our previous study [9].

\section{Catalyst Activity}

Different type of catalysts namely, Mg-Al HT, $\mathrm{Au} / \mathrm{Zn}-\mathrm{Mg}-\mathrm{Al} \mathrm{HT}$ and NAC were used for dark fermentation batch wise. Biohydrogen production experiments were conducted in $120 \mathrm{~mL}$ serum bottles with a working volume of $60 \mathrm{~mL}$. The power of metal catalysts at amount of $167 \mathrm{mg} / \mathrm{L}$ and the granular of carbon catalyst at $3.3 \times 10^{4} \mathrm{mg} / \mathrm{L}$ were added to synthetic medium comprised of sucrose at a concentration of $20 \mathrm{~g} / \mathrm{L}$, together with $5 \mathrm{~mL}$ of essential growth nutrients and $10-\mathrm{mL}$ of heat-treated sludge. The 
initial $\mathrm{pH}$ of 5.5 was adjusted using $1 \mathrm{~N} \mathrm{NaOH}$ or $1 \mathrm{~N} \mathrm{HCl}$. Anaerobic conditions were created by sparging with nitrogen gas for $3 \mathrm{~min}$. The cultivation bottles were operated under dark fermentation at $37^{\circ} \mathrm{C}$ with a stirrer of $90 \mathrm{rpm}$. The control batch was carried out without any addition of catalysts to estimate the promoting effect of catalysts on hydrogen production. The experiments were tested in triplicate. The amount of evolved gas was measured at room temperature by syringes.

\section{Chemical Analysis}

The gas compositions and volatile fatty acids (VFAs) were analyzed by a gas chromatograph and high performance liquid chromatograph respectively, in accordance with the condition described in our previous study [9]. The $\mathrm{pH}$ value was measured by a $\mathrm{pH}$ meter (Mettler Toledo, SevenGo ${ }^{\mathrm{TM}}$ SG2). COD, TSS, and VSS were determined in accordance with the procedures described in the Standard Methods [10].

\section{E. Kinetic Modeling}

The modified Gompertz model in Equation 1 is widely used to the progress of a batch fermentative hydrogen production process.

$$
H=H_{\text {max }} \exp \left\{-\exp \left[\frac{R_{m} * e}{H_{\max }}(\lambda-t)+1\right]\right\}
$$

where, $H$ and $H_{\max }$ denote the cumulative hydrogen production $(\mathrm{mL})$ and the maximum hydrogen production $(\mathrm{mL})$, respectively. $\mathrm{R}_{\mathrm{m}}$ represents the hydrogen production rate $(\mathrm{mL} / \mathrm{h}), \lambda$ the lag-phase time $(\mathrm{h})$, and $t$ the cultivation time (h).

\section{RESUlTS AND DisCUSSION}

\section{A. Biological Hydrogen Potential Using Carbon and Metal Catalysts}

Dark fermentative hydrogen production experiments were investigated over carbon catalyst, namely NAC, as well as metal catalysts, namely $\mathrm{Mg}-\mathrm{Al} \mathrm{HT}$ and $\mathrm{Au} / \mathrm{Zn}-\mathrm{Mg}-\mathrm{Al} \mathrm{HT}$. The optimum catalyst dose of each catalyst was reported in our previous study [9]. In this study, the optimum dose of

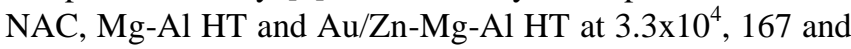
$167 \mathrm{mg} / \mathrm{L}$, respectively, were added in the fermentation mixture. Batch experiments were carried out until the hydrogen production from each bottle stopped. The data clearly indicated that the addition of all catalysts increased the production of hydrogen. The daily volumetric hydrogen production was reported on Fig. 1. The hydrogen production profiles showed that the initial activity of NAC is more active than HT catalysts. On the contrary, the activity of HT catalysts is more stable than NAC. Indeed, when hydrogen produced, the release of soluble metabolites in the medium decreased the $\mathrm{pH}$ down to inhibiting level. After 7 days, NAC test showed an inhibiting effect with low hydrogen production. By contrast, the addition of $\mathrm{Mg}-\mathrm{Al} \mathrm{HT}$ and $\mathrm{Au} / \mathrm{Zn}-\mathrm{Mg}-\mathrm{Al} \mathrm{HT}$ remained active and stable even after 7 days of fermentation in an acidic environment. This was due to the strong basic character of HTs. As the results, the pattern of hydrogen production was similar in both metal catalysts. However, the highest performances for hydrogen production were recorded over $\mathrm{Au} / \mathrm{Zn}-\mathrm{Mg}-\mathrm{Al} \mathrm{HT}$ with the maximum hydrogen yield of $2.74 \pm 0.14 \mathrm{~mol} \mathrm{H}_{2} / \mathrm{mol}$ sucrose. This result is about two times higher than that obtained from the control, in which the hydrogen yield was $1.36 \pm 0.10 \mathrm{~mol}$ $\mathrm{H}_{2} /$ mol sucrose. The use of Au catalysts has more beneficial effect on hydrogen yield than non-modified Mg-Al HT. This is due to the interactions between $\mathrm{Au}$ and the $\mathrm{Zn}-\mathrm{Mg}-\mathrm{Al} \mathrm{HT}$ support which play a role in the improvement of the hydrogen production. In case of $\mathrm{Au} / \mathrm{Zn}-\mathrm{Mg}-\mathrm{Al} \mathrm{HT}$ and NAC catalysts, different profiles of the hydrogen production curves were observed. It is due to the different mechanism of catalysts on hydrogen production. The mechanism of each catalyst was further explained in the later section.

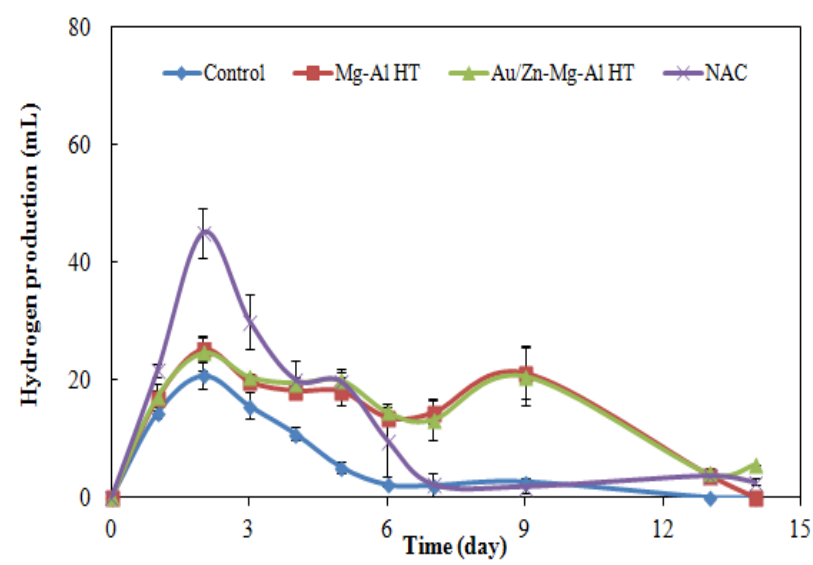

Fig. 1. Profile of hydrogen production using difference catalysts.

\section{B. Hydrogen Production Rate and Yield}

Estimated value of parameters and hydrogen yield are reported in Table I. It confirms that $\mathrm{H}_{\max }$ were achieved for $\mathrm{Au} / \mathrm{Zn}-\mathrm{Mg}-\mathrm{Al} \mathrm{HT}$. It is interesting that $\mathrm{R}_{\mathrm{m}}$ obtained from the NAC catalysts was higher than that of Au/Zn-Mg-Al HT catalyst addition. The addition of all catalysts has an influence on the kinetic of hydrogen production. The lag phase varies between 4 and $18 \mathrm{~h}$ for all the tests. As compare to $\mathrm{Au} / \mathrm{Zn}-\mathrm{Mg}-\mathrm{Al}$, a higher dose of NAC was required to reach the hydrogen yield of $2.60 \pm 0.15 \mathrm{~mol} \mathrm{H}_{2} / \mathrm{mol}$ sucrose. The results indicated that HTs based catalyst shows the better performance for fermentative hydrogen production.

TABLE I: ESTIMATEd VALUE OF PARAMETERS BY THE MODIFIED GOMPERTZ EQUATION AND HYDROGEN YIELD

\begin{tabular}{|c|c|c|c|c|c|c|}
\hline \multirow{2}{*}{ HTs } & Optimal dose & $\mathrm{H}_{\max }$ & $\mathrm{R}_{\mathrm{m}}$ & $\lambda$ & \multirow{2}{*}{$\mathrm{R}^{2}$} & \multirow{2}{*}{$\mathrm{H}_{2}$ yield* } \\
\hline & $(\mathrm{mg} / \mathrm{L})$ & $\left(\mathrm{mL} \mathrm{H}_{2}\right)$ & $\left(\mathrm{mL} \mathrm{H}_{2} / \mathrm{h}\right)$ & (h) & & \\
\hline Control & 0 & 104.2 & 0.8 & 6.6 & 0.998 & $1.60 \pm 0.10$ \\
\hline $\mathrm{Mg}-\mathrm{Al}$ & 167 & 150.8 & 1.1 & 4.0 & 0.998 & $2.30 \pm 0.37$ \\
\hline $\mathrm{Au} / \mathrm{Zn}-\mathrm{Mg}-\mathrm{Al}$ & 167 & 175.5 & 0.9 & 6.3 & 0.998 & $2.74 \pm 0.14$ \\
\hline NAC & $3.3 \times 10^{4}$ & 147.1 & 2.0 & 18.5 & 0.999 & $2.60 \pm 0.15$ \\
\hline
\end{tabular}

*(mol H$/$ mol sucrose $)$ 

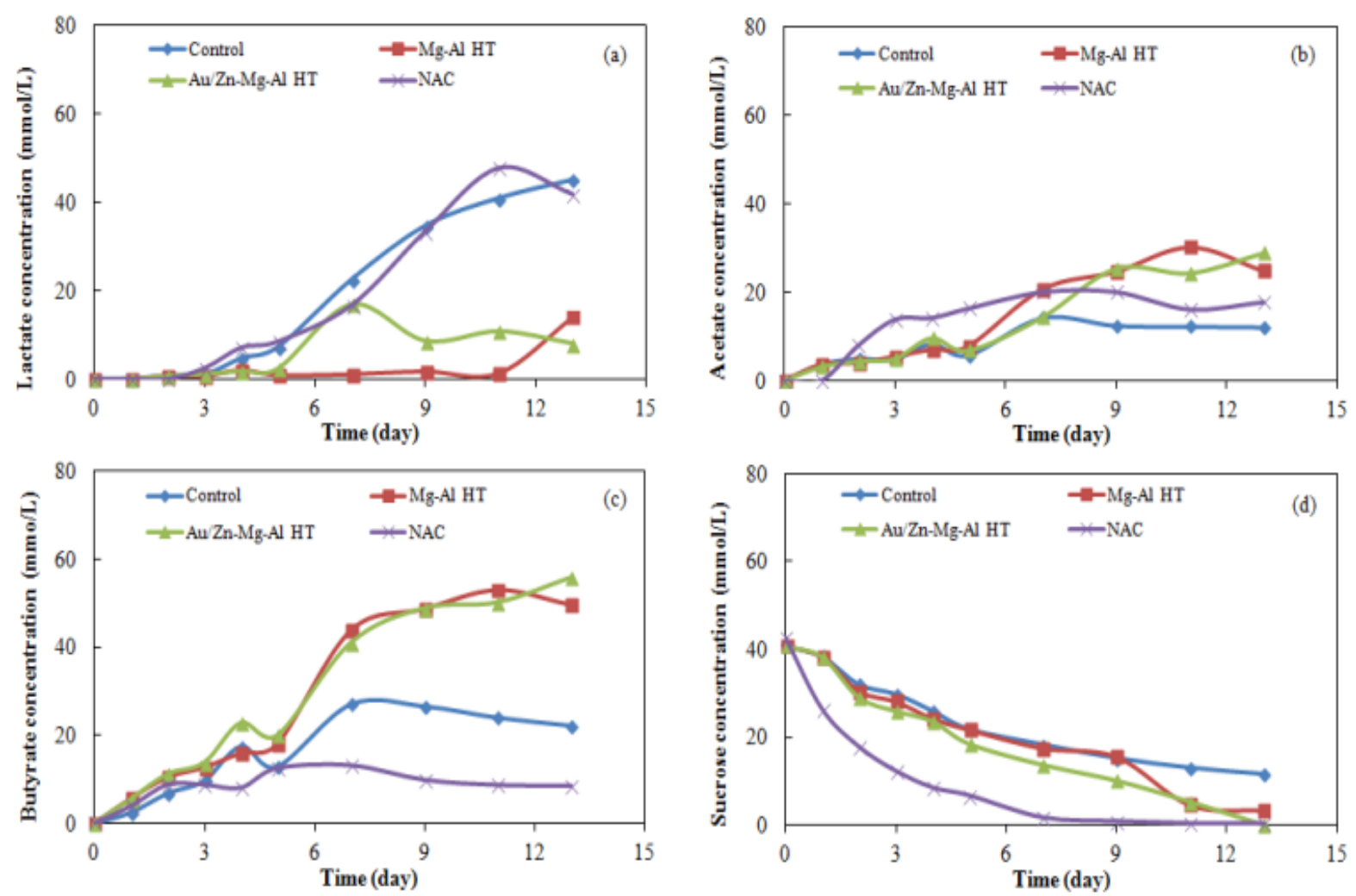

Fig. 2. The metabolites concentration of lactic acid (a), acetic acid (b), butyric acid (c) and sucrose (d) during investigation over carbon and metal catalysts.

\section{Effect of Catalysts on Metabolites}

As showed in Fig. 2, different types of catalysts resulted in different metabolites concentration. A higher concentration of acetic acid was found in NAC test, resulting in a higher hydrogen production during initial stage. The result indicates that production of acetic acids favors the production of hydrogen. During fermentation, a decrease in $\mathrm{pH}$ level induced a change in the main fermentation pathway. As the result, the pathways of lactic acid occurred when the $\mathrm{pH}$ was below 3. This phenomenon can inhibit the growth of hydrogen producing bacteria that resulted in a decrease in hydrogen production. It is of interest that a lower concentration of butyric acid was observed in NAC test as compared to control. It is possible that butyric acid was adsorbed on porous structure of NAC. In order to confirm this hypothesis, the absorption of VFAs on NAC was investigated. The result showed that high capacity of absorption of $77 \%$ was found for butyric acid (Fig. 3). On the contrary, about $10 \%$ of lactic acid and acetic acid was absorbed. This result suggested that NAC have no effect on acetic acid. The presence of NAC could minimize the concentration of butyric acid in fermentation broth to $8 \mathrm{mmol} / \mathrm{L}$. In case of metal catalysts, the higher concentrations of butyric acid and acetic acid and a lower concentration of lactic acid resulted in the higher hydrogen yield as compared to control. As a result, butyric acid was observed as the main metabolic product responsible for hydrogen production. After 7 days of fermentation, high yield of hydrogen were associated with a mixture of acetic acid and butyric acid as fermentation products. Thus, the addition of metal catalysts was effectively direct metabolism away from lactic acid and towards acetic acid and butyric acid as end fermentation products.

In this study, Au/Zn-Mg-Al HT showed a higher performance than $\mathrm{Mg}-\mathrm{Al} \mathrm{HT}$. The reason for a high activity of $\mathrm{Au} / \mathrm{Zn}-\mathrm{Mg}-\mathrm{Al} \mathrm{HT}$ was relate to the combination effects of the metallic dispersion of $\mathrm{Au}$ on the $\mathrm{Zn}-\mathrm{Mg}$-Al HT support. Zinc can act as a bridge between the substrate and enzyme increasing the binding energy. This is due to that zinc is present in the active site of several enzymes such as dehydrogenase and hydrogenase [11]. In addition, high activity was achieved with the gold catalysts which served as electron sinks. A high affinity for electrons allows further reduction of protons to hydrogen [6].

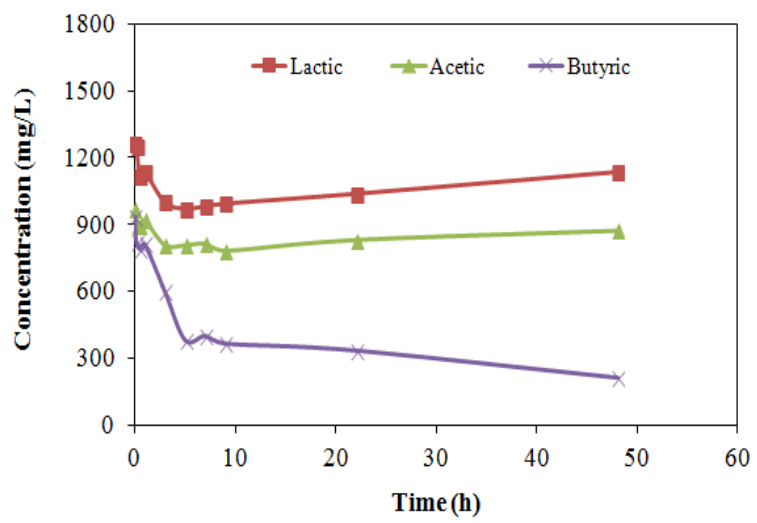

Fig. 3. Volatile fatty acid absorption on NAC during fermentation.

\section{CONCLUSION}

The addition of catalysts including carbon and metal catalysts significantly improves the efficiency of hydrogen production in fermentation process. Interaction between $\mathrm{Au}$ and $\mathrm{Zn}-\mathrm{Mg}$-Al HT support has been assumed for improving bioactivity. In case of $\mathrm{NAC}$, the increase in hydrogen production yield was assigned to the prevention of accumulation of butyric acid on NAC. A lower concentration 
of butyric acid obtained from NAC test showed positive effect on hydrogen production as compared to control. The different types of catalyst exhibited significant change in the metabolic pathways, regarding the hydrogen yield and soluble metabolites distribution.

\section{ACKNOWLEDGMENT}

The authors gratefully acknowledge financial support from the Thailand Research Fund (TRF) under the Royal Golden Jubilee (RGJ) Ph.D. Program to Ms. Pornthip Wimonsong and the Higher Education Research Promotion and National Research University Project of Thailand, Office of the Higher Education Commission for the research on biohydrogen production.

\section{REFERENCES}

[1] S. K. Han and H. S. Shin, "Biohydrogen production by anaerobic fermentation of food waste," Int. J. Hydrogen Energy, vol. 29, no. 6, pp. 569-577, May 2004.

[2] R. Lakshmidevi and K. Muthukumar, "Enzymatic saccharification and fermentation of paper and pulp industry effluent for biohydrogen production," Int. J. Hydrogen Energy, vol. 35, no. 8, pp. 3389-3400, April 2010.

[3] Y. V. Bhaskar, S. V. Mohan, and P. N. Sarma, "Effect of substrate loading rate of chemical wastewater on fermentative biohydrogen production in biofilm configured sequencing batch reactor," Bioresour Technol., vol. 99, no. 15, pp. 6941-6948, Oct. 2008.

[4] Y. Sharma and B. Li, "Optimizing hydrogen production from organic wastewater treatment in batch reactors through experimental and kinetic analysis," Int. J. Hydrogen Energy, vol. 34, no. 15, pp. 6171-6180, Aug. 2009

[5] P. Prasertsan, S. O. Thong, and N. K. Birkeland, "Optimization and microbial community analysis for production of biohydrogen from palm oil mill effluent by thermophilic fermentative process," Int. J. Hydrogen Energy, vol. 34, no. 17, pp. 7448-7459, Sep. 2009.
[6] Y. Zhang and J. Shen, "Enhancement effect of gold nanoparticles on biohydrogen production from artificial wastewater," Int. J. Hydrogen Energy, vol. 32, no. 1, pp. 17-23, Jan. 2007.

[7] W. Zhao, J. Zhao, G. Chen, R. Feng, J. Yang, Y. Zhao, Q. Wei, B. Du, Y. Zhang, "Anaerobic Biohydrogen production by the mixed culture with Mesoporous $\mathrm{Fe}_{3} \mathrm{O}_{4}$ nanoparticles activation," Adv. Mat Res, vol. 306-307, pp. 1528-1531, Aug. 2011

[8] H. Han, M. Cui, L. Wei, H. Yang, and J. Shen, "Enhancement effect of hematite nanoparticles on fermentative hydrogen production," Bioresour Technol., vol. 102, no. 17, pp. 7903-7909, Sep. 2011.

[9] P. Wimonsong, J. Llorca, and R. Nitisoravut, "Catalytic activity and characterization of Fe-Zn-Mg-Al hydrotalcites in biohydrogen production," Int. J. Hydrogen Energy, vol. 38, no. 25, pp. 10284 -10292, Aug. 2013.

[10] APHA, Standard Methods for the Examination of Water and Wastewater, American Public Health Association, 19th ed. Washington, DC, USA; 1995.

[11] J. Wang and W. Wan, "Factors influencing fermentative hydrogen production: a review," Int. J. Hydrogen Energy, vol. 34, no. 2, pp. 799-811, Jan. 2009.

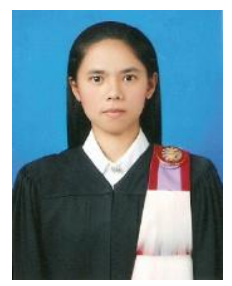

Pornthip Wimonsong received her master and bachelor degrees in environmental science in Thailand. At present, she is a doctoral candidate at School of Bio-Chemical Engineering and Technology, Sirindhorn International Institute of Technology, Thammasat University, Thailand.

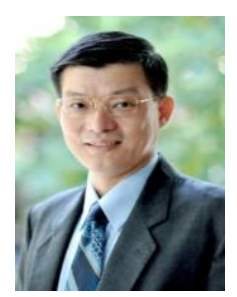

Rachnarin Nitisoravut received his Ph.D. in civil, environmental engineering from North Carolina State University, NC, USA. He is an associate professor at School of Bio-Chemical Engineering and Technology, Sirindhorn International Institute of Technology, Thammasat University, Thailand. His research interests are environmental biotechnology, microbiology, biological treatment of water and wastewater, low-carbon research. 